\title{
A Note on Priest's Mereology
}

\author{
A.J. Cotnoir \\ Departments of Philosophy \\ University of St. Andrews \\ ac117@st-andrews.ac.uk
}

In the last several years, paraconsistent mereology has begun to be developed and applied to a range of philosophical issues, from puzzles about boundaries [13], to the Meinongian 'problem of nothingness' $[1,2,10]$, to the metaphysics of unity [9]. Because these formal systems are fresh out of the package, as it were, there will inevitably be some wrinkles that need ironing out. In this note, I'll point out a problem with the systems in Priest $[9,10]$, and suggest a way to fix them.

Priest's [10] mereology uses the proper parthood relation as its primitive, symbolized by $<$. He defines the parthood relation $\leq$ using the standard definition: $x \leq y: \equiv x<y \vee x=y$; he also defines mereological overlap $\circ$ as $x \circ y: \equiv \exists z(z \leq x \wedge z \leq y) .{ }^{1}$ Here are his axioms:
(1) $\forall x \forall y(x<y \rightarrow \neg y<x)$
Asymmetry
(2) $\forall x \forall y((x<y \wedge y<z) \rightarrow x<z)$
Transitivity
(3) $\forall x \forall y(\forall z(z \circ x \leftrightarrow z \circ y) \rightarrow x=y)$
Extensionality
(4) $\forall X \exists y \forall z(z \circ y \leftrightarrow \exists x(x \in X \wedge z \circ x))$
Unrestricted Fusion

The first two axioms state that proper parthood is a strict ordering on the domain; these are principles Priest accepts as "a standard assumption (that I will not challenge here)" [10, p. 148]. The next axiom is that objects are extensionally defined via their overlappers; and the final is an unrestricted principle of fusion based on a definition from Goodman [5]. ${ }^{2}$

\footnotetext{
${ }^{1}$ Priest uses $\mathfrak{E}$ and $\mathfrak{A}$ for quantifiers instead of $\exists$ and $\forall$, as he is working in a Meinongian framework with neutral quantification. For our purposes, however, the difference makes little difference.

${ }^{2}$ Strictly speaking, Priest [10] is only committed to there being fusions for every set, not the existence of such a fusion.
}

Australasian Journal of Logic (15:4) 2018, Article no. 1 
A similar system is found in Priest [9, ch. 6], except that there Priest rejects Asymmetry and its correlate Antisymmetry.

$$
\forall x \forall y((x \leq y \wedge y \leq x) \rightarrow x=y) \quad \text { Antisymmetry }
$$

The rejection of (5) is crucial to Priest's metaphysics of unity, due to a substitution argument involving 'prime gluons' (p. 89).

But the problem is that (5) is entailed by (2) and (3). ${ }^{3}$ Assume $x \leq y$ and $y \leq x$. From the former, it actually follows that $\forall z(z \circ x \rightarrow z \circ y)$ : for assume $z \circ x$ i.e. $\exists w(w \leq z \wedge w \leq x)$; by (2), $w \leq y$ and so $z \circ y$. Similarly from $y \leq x$ we have $\forall z(z \circ y \rightarrow z \circ x)$, and so $\forall z(z \circ x \leftrightarrow z \circ y)$. By $(3), x=y$.

This means, crucially, that in order for Priest's systems to undergird the applications in [9], (3) must go. Perhaps, then, Priest can treat this 'problem' as simply a sound argument for rejecting (3). Problem solved?

Not exactly. For once (3) is rejected, a whole new range of problems crop up, particularly to do with the definition of fusion. Consider the following two models (where upward arrows indicate parthood).
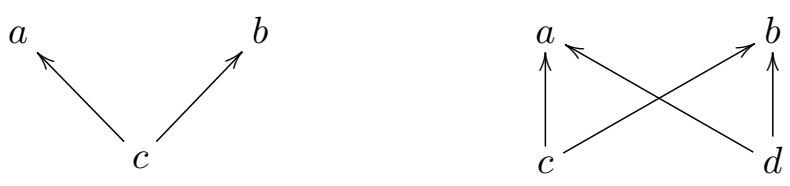

Figure 1: Bad fusions

Look first at the diagram on the left of figure 1, which displays a model in which everything overlaps everything; in particular, something overlaps $c$ if and only if it overlaps either $a$ or $b$. Counterintuitively, then, this means that $c$ is a fusion of $\{a, b\}$. Oddly, though, $c$ isn't even an upper bound of $a$ and $b$; it doesn't even have $a$ or $b$ as parts! Another case in point is the non-

\footnotetext{
${ }^{3}$ Here I assume the underlying paraconsistent logic is such that $\rightarrow$ detaches, as it does in $B X$ (see Priest [10, fn. 16]). If one is using a non-detachable conditional, such as the material conditional of $L P$, then all the axioms of the theory - especially (4) — are much weaker that one would have hoped (see Priest [10, §8]).
} 
extensional model on the right, where $a$ turns out to be fusion of $\{a, b\}$ even though $b$ is not part of $a$ (and vice versa). This shows clearly that things can go badly wrong with the definition fusions in such non-extensional models.

What to do? There are a number of options. We could mess around with the definition of fusions. Here are three prominent definitions of fusions found in the literature.

(6) $\quad F_{X} z: \equiv \forall x(x \in X \rightarrow x \leq z) \wedge \forall y(\forall x(x \in X \rightarrow x \leq y) \rightarrow z \leq y) \quad$ Algebraic Fusions

(7) $F_{X}^{\prime} z: \equiv \forall x(x \in X \rightarrow x \leq z) \wedge \forall y(y \leq z \rightarrow \exists x(x \in X \wedge y \circ x)) \quad$ Leśniewski Fusions

(8) $F_{X}^{\prime \prime} z: \equiv \forall y(y \circ z \leftrightarrow \exists x(x \in X \wedge y \circ x))$

Goodman Fusions

Priest relies on (8), but he might have more success with either (6) which is used in [13] and subsequently in [1, ch. 4] and [2,3]. Alternatively, he might try the historic (7) used [6], [11], and popularized by [8]. ${ }^{4}$

But instead of pursuing other definitions of fusion, a simpler fix would be to recover some missing structure by adding an axiom that falls just short of extensionality.

$$
\forall x \forall y(\forall z(z \circ x \rightarrow z \circ y) \rightarrow x \leq y) \quad \text { Strong Supplementation }
$$

This principle is one of a family of so-called Supplementation principles, which forces objects to be decomposed in intuitive ways. It is easy to see that this principle eliminates the problem with the above models, since it requires that whenever $x$ 's overlappers includes $y$ 's overlappers, then $x$ includes $y$. A fusion, then, will always be an upper bound of the things it fuses.

I say that (9) 'falls just short of extensionality' because when $x$ and $y$ have the same overlappers, it follows that $x \leq y$ and $y \leq x$. However, the inference to $x=y$ is blocked because we don't in general have (5).

To sum up, the mereology given in Priest [9] is inadequate for his purposes, due to the presence of antisymmetry and extensionality. But a good fix is not too far away.

\footnotetext{
${ }^{4}$ For more on the various definitions of fusion in non-antisymmetric (albeit classical) contexts, see [4].
} 


\section{References}

[1] Casati, F. Being: A Dialetheic Interpretation of the Late Heidegger. PhD thesis, University of St Andrews, St Andrews, 2016.

[2] Casati, F., And Fujikawa, N. Better than zilch? Logic and Logical Philosophy 24 (2015), $255-264$.

[3] Casati, F., and Fujikawa, N. Nothingness, Meinongianism and inconsistent mereology. Synthese (in press).

[4] Cotnoir, A. J. Does universalism entail extensionalism? Nô̂s 50 (2016), 121-132.

[5] Goodman, N. The Structure of Appearance. Harvard University Press, Cambridge (MA), 1951. 3rd edition: Reidel, Dordrecht, 1977.

[6] LeŚniewski, S. Podstawy ogólnej teoryi mnogości. I. Prace Polskiego Koła Naukowego w Moskwie, Sekcya matematyczno-przyrodnicza, Moskow, 1916. Eng. trans. by D. I. Barnett: Foundations of the general theory of sets. I, in [7], pp. 129-173.

[7] LeŚniewski, S. Collected Works. Kluwer, Dordrecht, 1992. Edited by S. J. Surma, J. T. Srzednicki, D. I. Barnett, and F. V. Rickey.

[8] Lewis, D. K. Parts of Classes. Blackwell, Oxford, 1991.

[9] Priest, G. Much ado about nothing. Australasian Journal of Logic 11 (2014), 146-158.

[10] Priest, G. One, Being an Investigation into the Unity of Reality and of its Parts, including the Singular Object which is Nothingness. Oxford University Press, Oxford, 2014.

[11] Tarski, A. Les fondements de la géométrie des corps. Ksiega Pamiatkowa Pierwszkego Polskiego Zjazdu Matematycznego, suppl. to Annales de la Société Polonaise de Mathématique 7 (1929), 29-33. Eng. trans. by J. H. Woodger (with additions): Foundations of the geometry of solids, in [12], pp. 24-29.

[12] TARski, A. Logic, Semantics, Metamathematics. Papers from 1923 to 1938. Clarendon Press, Oxford, 1956.

[13] Weber, Z., And Cotnoir, A. J. Inconsistent boundaries. Synthese 192, 5 (2015), 1267-1294. 